\title{
Outcome of Distal End Clavicle Fractures Treated with Locking Plates
}

\section{Ashwin Chauhan', Vasant Gawande ${ }^{2}$, Kunal K Saoji ${ }^{3}$, Ankit Mittal ${ }^{4}$, Suvarn Gupta 5}

\begin{abstract}
Senior Resident, Department of Orthopedics, Jawaharlal Nehru Medical College, Datta Meghe Institute of Medical Sciences, Sawangi, Wardha, Maharashtra-4422001; ${ }^{2}$ Associate Professor, Department of Orthopedics, Jawaharlal Nehru Medical College, Datta Meghe Institute of Medical Sciences, Sawangi, Wardha, Maharashtra-4422001; ${ }^{3}$ Assistant Professor, Department of Orthopedics,Datta Meghe Medical College, Shalinitai Meghe Hospital and Research Centre. (SMHRC), Wanadongri, Hingna, Nagpur-441110; 4Junior Resident Department of Orthopedics, Jawaharlal Nehru Medical College, Datta Meghe Institute of Medical Sciences, Sawangi, Wardha, Maharashtra-4422001; ${ }^{5}$ Assistant Professor, Department of Orthopaedics, Jawaharlal Nehru Medical College, Datta Meghe Institute of Medical Sciences, Wardha, Maharashtra-442001.

\section{ABSTRACT}

Background: Clavicle fractures are one of the commonest fractures with accounts of $3 \%$ of all injuries. Lateral end clavicle fracture contributes $25 \%$ of clavicle fractures and out of that $10-52 \%$ is unstable which requires various surgical fixations for better functional outcome. The aim of our study is to find out functional outcome following surgical fixation with locking plates.

Methods: It is the prospective study conducted at Shalinitai Meghe Hospital, Nagpur from June 2019 to April 2020 (11 months) in 66 patients admitted at our hospital for surgical management.

Results: 66 patients aged from 18-40 years with a mean age group of 29 years with 44 patients were right-sided clavicle fractures. Meantime for trauma to surgery was 76 hours with a mean operative time of 60 min. The average time for bony union of fracture was noted to be around two and a half months. After 8 weeks and 24 weeks, the Mean DASH score was found to be 4.6 and 11.63, respectively. The functional results were Excellent in 24 (36.36\%), Good in 40 (60.6\%), Fair in 1 (1.51\%), and Poor in $1(1.51 \%)$ patients according to the DASH score.

Conclusion: Though there are various surgical methods for fixing such unstable variety of lateral clavicle fracture, the gold standard treatment option is debatable and challenging. But we found in our study, the functional outcome after using a precontoured locking plate for such cases is beneficial and satisfactory.

Key Words: Distal end clavicle fracture, Unstable fracture, Pre contoured locking plate, Trauma, Neer's Classification

\section{INTRODUCTION}

Clavicle fractures are considered to be among the commonest fracture occurring in daily living and as one of the commonest in adults which accounts for approximately 3 percent of all injuries ${ }^{1}$. This type of fracture occurs due to fall or trauma on outstretched hand or can be because of direct trauma to the chest or shoulder region. Mid-shaft is the frequent site of clavicle fracture and followed by lateral end clavicle which is about 25 percent of all ${ }^{2,3}$ Approx 10- 52\% of these fractures are displaced and unstable type $e^{1,4,5}$ due to deforming forces acting on the clavicle are sparse where lateral end moves inferiorly and medial end moves antero superiorly. Clavicle fractures are classified on the basis of Neer's Classification $^{6}$. It is difficult to reduce this fracture anatomically because of the smaller lateral fragment of clavicle leading to a higher incidence of instability.

Various management options have been invented in the past for these unstable varieties ranging from non-operative to operative modalities. $22-50 \%$ of cases managed conservatively go into non-union which is too high ${ }^{7-9}$. Among these $14 \%$ of cases become symptomatic ${ }^{8}$. Wide varieties of operative management have been implemented in treating lateral end clavicle fixation including ligament reconstruction. Modalities like Kirschner wires ${ }^{10}$, Locking ${ }^{11-15}$ and non locking plates ${ }^{16}$, hook plate ${ }^{17,18}$, tension bands suturing ${ }^{19,20,21,22}$, coracoclavicular screws $^{23-25}$. Few known complications noted with an operative modality such as malunion or non-union fracture, impingement of hardware, bleeding, pin migration, implant removal ${ }^{16,17}$.

\section{Corresponding Author:}

Dr. Vasant Gawande, Associate Professor, Department of Orthopedics, Jawaharlal Nehru Medical College, Datta Meghe Institute of Medical Sciences, Sawangi, Wardha, Maharashtra-4422001.

ISSN: 2231-2196 (Print)

Received: 16.05 .2020
ISSN: 0975-5241 (Online)

Revised: 09.06 .2020
Accepted: 16.06 .2020
Published: 21.07 .2020 
In our study, we examined the radiological and functional results in the younger group of patients who used a locking plate to repair the lateral end fractures of the clavicle.

\section{MATERIALS AND METHODS}

\section{Patients}

We conducted our study in Dept. of Orthopedics at Jawaharlal Nehru Medical College, Datta Meghe Institute of Medical Sciences, Sawangi, Wardha in collaboration with Datta Meghe Institute of Medical Sciences, Shalinitai Meghe Hospital and Research Center, Nagpur from June 2019 to April 2020.

For the study, all patients with an acute distal end clavicle fracture were included. We removed patients over 7 days old with fractures, as well as patients with suspected neuro-vascular injuries. Many of the patients were adults, and this analysis included no children. For this study, 66 patients were included with informed consent had been received. Surgery was planned after the patients' initial management, and the patient was operated as soon as possible. We used $3.5 \mathrm{~mm}$ pre-contoured locking plate with lateral extension in all cases for Open reduction and internal fixation (ORIF) as shown in the figure.

\section{Surgery}

Under general anesthesia a single surgeon had performed all surgeries, in the anatomically lying down position on the table with a sandbag kept in between the scapula to make clavicle more prominent. To get a better view of the operation site the patient's head was turned to the opposite side. The superior clavicle was taken over by a lateral incision, centering the fractures. Subcutaneous dissection, which took care of the supraclavicular nerves followed. The Clavicle was revealed by the platysma division. We temporarily reduced the fracture and maintain it with the help of Kirchner wire and then stabilized the fracture with pre-contoured $3.5 \mathrm{~mm}$ locking plate with the lateral extension as shown in figure. For this plate we used $2.7 \mathrm{~mm}$ locking screw to hold the lateral end (Distal fragment of the clavicle) and $3.5 \mathrm{~mm}$ cortical screw to hold the medial end of plate (Proximal fragment).

\section{Postoperative care}

In all the scenarios the postoperative duration was unincidental. All the patients were given an arm pouch. Immediate (post op day 1) mobilization of wrist and elbow had been advised. Post op check dressing was done after 48 hours and later patients were discharged. Suture removal was done on $10^{\text {th }}$ day post op when patients came for their $1^{\text {st }}$ follow up. We removed the arm pouch and shoulder mobilization started after 3 weeks post op. Radiological assessment was done after 6 weeks postoperative for radiological signs of the union.
We used the Visual Analog Scale (VAS) for postoperative assessment of pain on immediate post op, on $1^{\text {st }}$ check dressing, and on day of suture removal. Analgesics were discontinued after $1^{\text {st }}$ check dressing. We also used the Arm, Shoulder, and Hand Disabilities (DASH) scoring system for assessing clinical outcome at 8 and 24 weeks post-operatively. The patient was followed until the bony union is achieved.

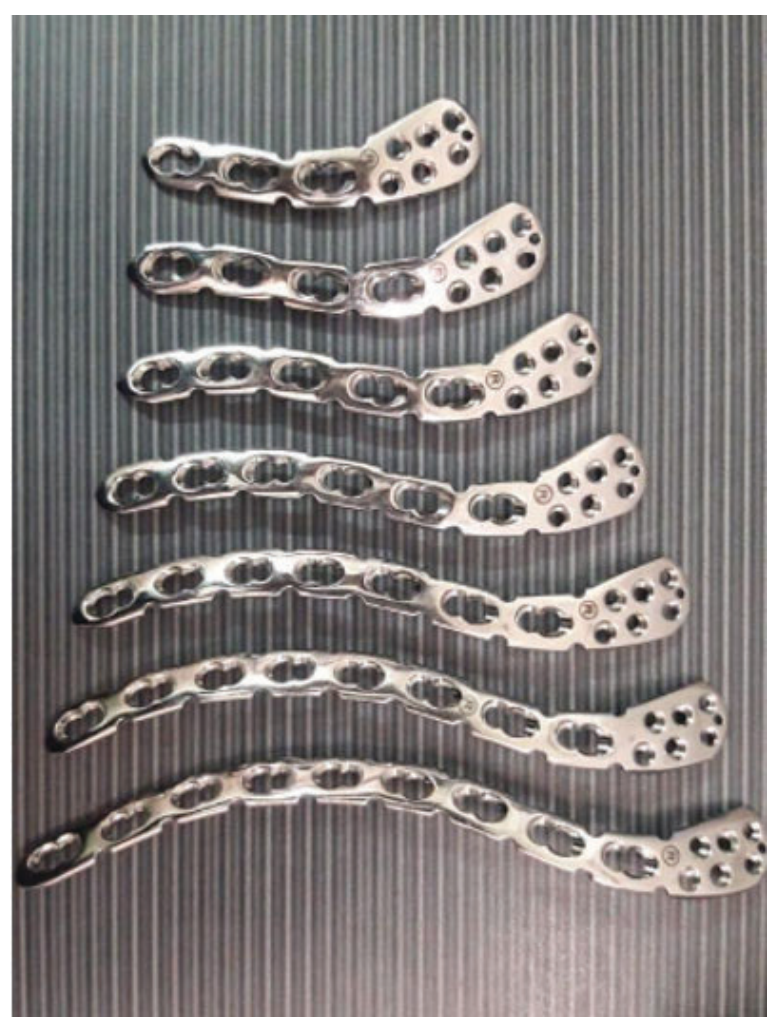

Figure 1: Anatomical pre-contoured locking plate for distal end of clavicle.

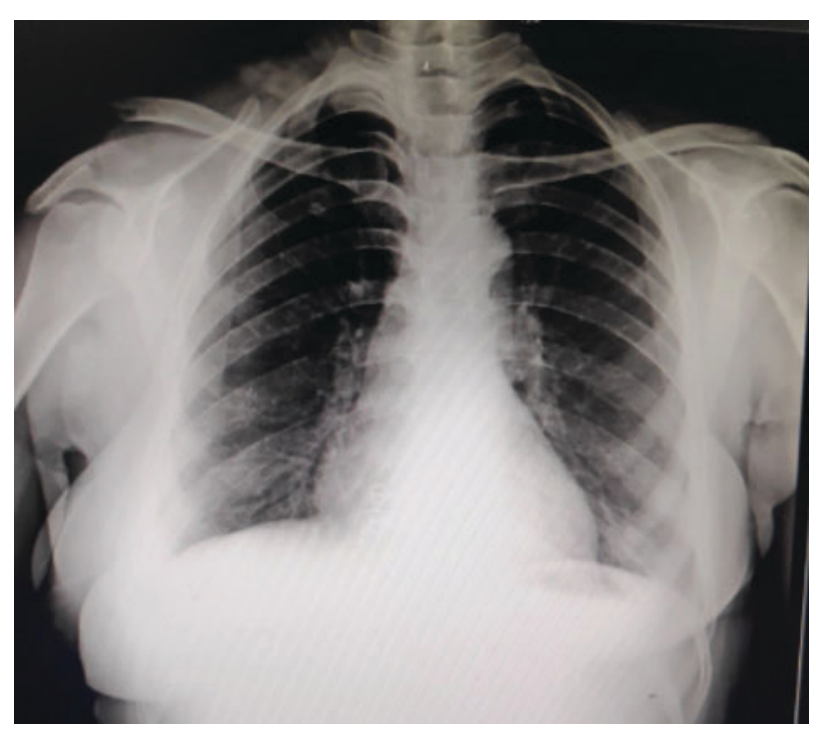

Figure 2: Pre operative X-ray of Patient 1 (35 years old female). 


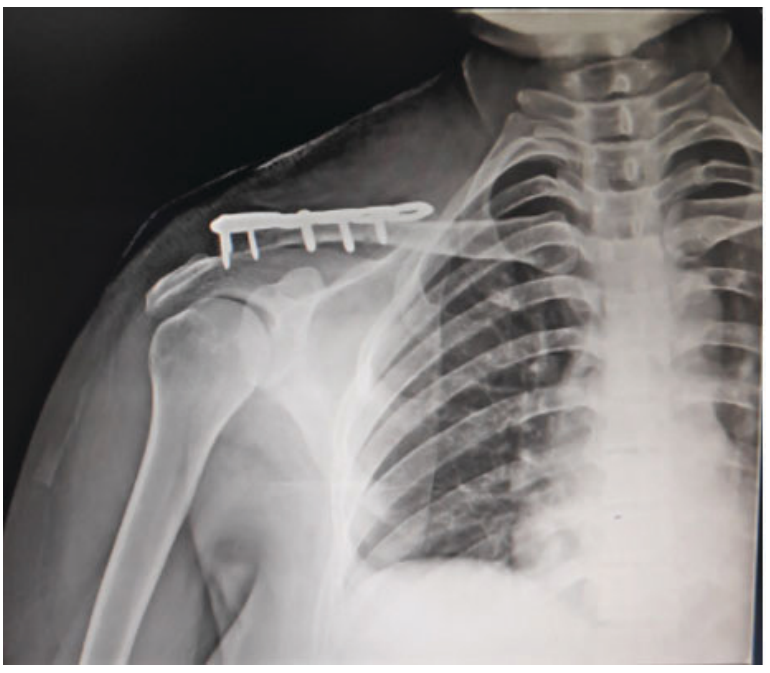

Figure 3: Post Operative X-Ray of Patient 1 (35 years old female).

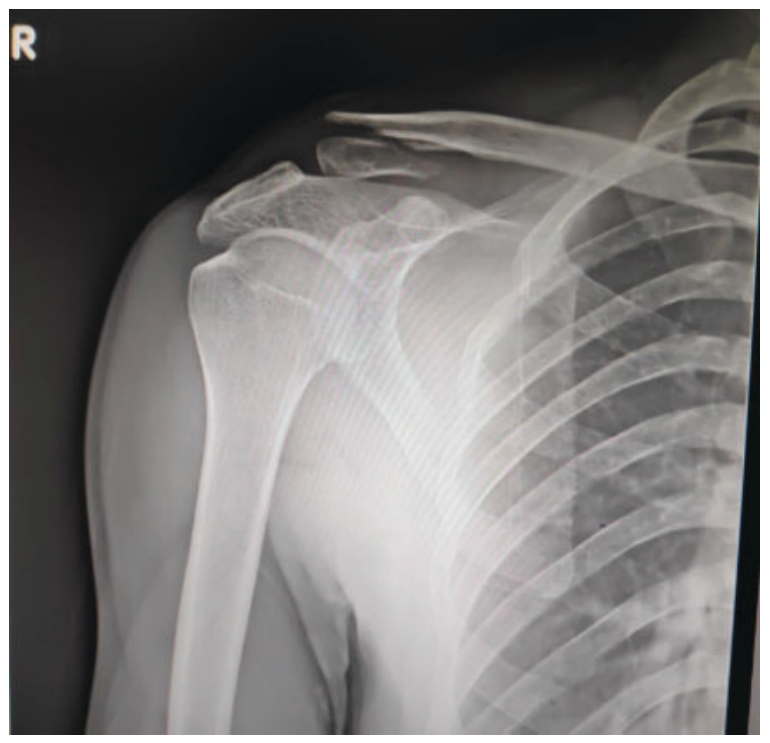

Figure 4: Pre Operative X-ray of Patient 2 (25 years Male).

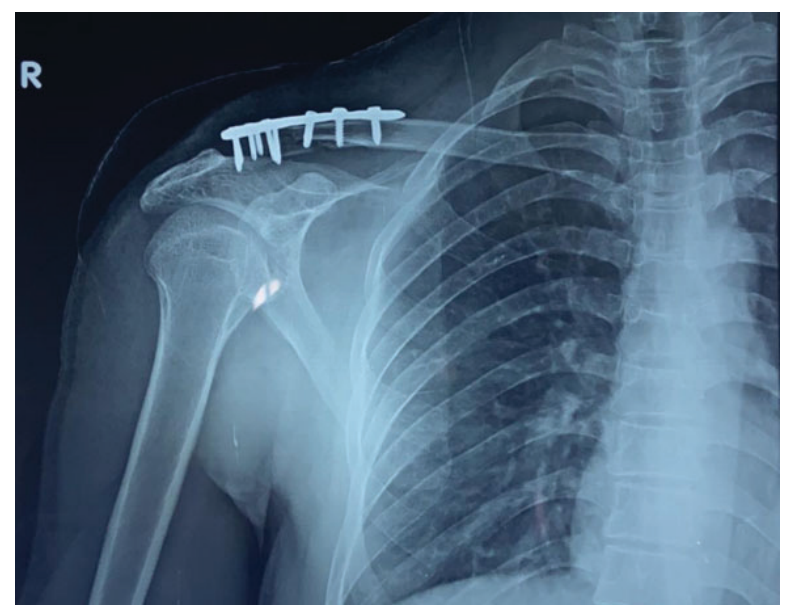

Figure 5: Post Operative X-ray of Patient 2 (25 years Male).

\section{RESULTS}

We included Sixty-six cases of distal end clavicle fracture in our study, with 69.69 percent (46 cases) of right clavicle fracture. Bilateral clavicle fractures have not been confirmed. The age ranging from 18 to 40 years, with an average age of 29 years were included. Among these 44 patients had road traffic accidents, 22 patients having a history of falls at home. The mean operating time for fixation after the injury was 3 days (ranging from 8 h to 6 days). Neither individual had distal neurovascular defects. The operating time varied between 45 and $75 \mathrm{~min}$ (average: $60 \mathrm{~min}$ ). Almost in all cases, pre-contoured anatomical plates were used as per the fracture pattern. All the surgeries went uneventful and as per our routine protocol, we rechecked the reduction and fixation radiologically on the same day and were found to be acceptable. No infection or neurovascular complication noted in any patients.

The VAS score on day 1 post op, after 48 hours post op and on $10^{\text {th }}$ day was found to be $5,3,0$, respectively. Average time for bony union of fracture was noted to be around 2 and half months. Among these cases only a single case of non-union and a single case of mal-union as a major complication were found. After 8 weeks and 24 weeks, the Mean DASH score was found to be 4.6 and 11.63 , respectively. The functional results were Excellent 24 (36.36\%), Good 40 (60.6\%), Fair 1 (1.51\%), and Poor 1 (1.51\%), according to the DASH score.

\section{DISCUSSION}

The most common injuries occurring in young adult groups are fractures of the clavicle. Ribs, ear, and upper extremities are most generally associated with injuries. Due to road traffic accidents, these fractures are found to be more common in the young population. The distal end of clavicle usually after road traffic accidents end up into multiple fragments, which need to be managed by good surgical reduction and fixation with the latest locking plates. With the introduction of newer fixation methods, the issues associated with its fixation, complications, and results are expected to be greatly reduced. Clavicle fractures have usually been treated by means which were not operative. A few decades ago the fracture of the distal end of the clavicle was invariably managed by conservative methods which usually end up with one or few complications resulting in decreased expected functional outcome.

The forces acting on the small distal fragment of the clavicle are very high leading to the failure of conservative treatment and therefore the need for stable fixation with properly designed plate is necessary which is full filled by locking plate.

The deforming forces which are responsible of instability at fracture site of the distal clavicle are ligaments (coracoacro- 
mial ligament and the coracoclavicular ligament) and muscles (trapezius and anterior fibers of deltoid) along with the weight of the upper limb.

Many surgeons try different modalities of treatment for treating the distal end of the clavicle. These surgical methods include $\mathrm{K}$-wire fixation, tension band wiring, coracoclavicular screw fixation, hook plates, reconstruction plate, and locking plates. Among the locking plates, the most fascinating plates to surgeons are anterior clavicular plates and pre-contoured lateral clavicular plates. The fascinating feature of this plate is that it fits anatomically well with the contour of the clavicle's distal end. The significance of multi-planar screw plate fixation gives stronger hold in osteoporotic bones and also neutralizes the forces acting on the smaller unstable distal fracture fragment.

Kalamaras et al. ${ }^{20}$ concluded that distal clavicle fracture treated with locking plates gives better functional outcomes. According to Rieser et al. ${ }^{25}$ locking plate for distal end clavicle fracture gives biomechanically stable fixation with good clinical outcomes.

In 13 cases of distal clavicle fractures reported by Anderson et al. ${ }^{26}$ showed higher union rates were supported by superior locking plates with superior functions and minimum complications.

Canadian orthopaedic society has published their study on functional results of clavicle fractures treated with operative intervention given good functional outcome as compared to conservative management ${ }^{27}$

K C Kapil- Mani et al. ${ }^{28}$ reported successful outcomes in fracture union of distal end clavicle fracture treated with precontoured locking plate with a minimal complication rate of implant failure, bursitis, AC joint arthritis, or iatrogenic cuff injuries.

\section{CONCLUSION}

The distal end of clavicle fractures is very peculiar which needs specific treatment with specially designed pre-contoured locking plates. The advantage of newly designed pre contoured plate for distal end clavicle are 1.) Well-fitting on the lateral contour of the clavicle, 2.) Low profile causing minimal soft tissue damage 3.) Multi-planar screw placement giving good purchase and superior stability 4.) The associated ligament injuries can also be managed through screw holes giving added advantages.

Acknowledgement: Authors acknowledge the immense help received from management of Datta Meghe Institute of Medical Sciences, Sawangi, India for providing support to conduct this study.

\section{Conflicts of Interest: Nil}

\section{Source of Funding: Nil}

\section{REFERENCES}

1. Robinson CM. Fractures of the clavicle in the adult: epidemiology and classification. The Journal of bone and joint surgery. British volume. 1998; 80(3):476-84.

2. Robinson CM, Cairns DA. Primary non-operative treatment of displaced lateral fractures of the clavicle. JBJS. $2004 \mathrm{Apr}$ $1 ; 86(4): 778-82$.

3. Khan LK, Bradnock TJ, Scott C, Robinson CM. Fractures of the clavicle. JBJS. 2009 Feb 1;91(2):447-60.

4. Nordqvist AN, Petersson CL. The incidence of fractures of the clavicle. Clinical orthopaedics and related research. 1994 Mar (300):127-32.

5. Postacchini F, Gumina S, De Santis P, Albo F. Epidemiology of clavicle fractures. Journal of Shoulder and Elbow Surgery. 2002 Sep 1;11(5):452-6.

6. CHARLES S NEER II. 5 Fractures of the distal third of the clavicle. Clinical Orthopaedics and Related Research (1976-2007). 1968 May 1;58: 43-50.

7. Nordqvist A, Petersson C, Redlund-Johnell I. The natural course of lateral clavicle fracture: 15 (11-21) year follow-up of 110 cases. Acta Orthopaedica Scandinavica. 1993 Jan 1;64(1):87-91.

8. Robinson CM, McQueen MM, Wakefield AE. Estimating the risk of nonunion following nonoperative treatment of a clavicular fracture. JBJS. 2004 Jul 1;86(7):1359-65.

9. Rokito AS, Zuckerman JD, Shaari JM, Eisenberg DP, Cuomo F, Gallagher MA. A comparison of nonoperative and operative treatment of type II distal clavicle fractures. Bulletin-Hospital for Joint Diseases. 2002 Dec 1;61(1-2):32-9.

10. Levy O. Simple, minimally invasive surgical technique for treatment of type 2 fractures of the distal clavicle. Journal of shoulder and elbow surgery. 2003 Jan 1;12(1):24-8.

11. Klein SM, Badman BL, Keating CJ, Devinney DS, Frankle MA, Mighell MA. Results of surgical treatment for unstable distal clavicular fractures. Journal of shoulder and elbow surgery. 2010 Oct 1;19(7):1049-55.

12. Herrmann S, Schmidmaier G, Greiner S. Stabilisation of vertical unstable distal clavicular fractures (Neer $2 b$ ) using locking Tplates and suture anchors. Injury. 2009 Mar 1;40(3):236-9.

13. Kaipel M, Majewski M, Regazzoni P. Double-plate fixation in lateral clavicle fractures - a new strategy. Journal of Trauma and Acute Care Surgery. 2010 Oct 1;69(4):896-900.

14. Oh JH, Kim SH, Lee JH, Shin SH, Gong HS. Treatment of distal clavicle fracture: a systematic review of treatment modalities in 425 fractures. Archives of orthopaedic and trauma surgery. 2011 Apr 1;131(4):525-33.

15. Chao YU, Sun YH, Zhao CQ, Shi DW, You WA. Treatment of distal clavicle fracture with distal radius volar locking compression plate. Chinese Journal of Traumatology (English Edition). 2009 Oct 1;12(5):299-301.

16. Kona J, Bosse MJ, Staeheli JW, Rosseau RL. Type II distal clavicle fractures: a retrospective review of surgical treatment. Journal of orthopaedic trauma. 1990;4(2):115-20.

17. Klein SM, Badman BL, Keating CJ, Devinney DS, Frankle MA, Mighell MA. Results of surgical treatment for unstable distal clavicular fractures. Journal of shoulder and elbow surgery. 2010 Oct 1;19(7):1049-55.

18. Haidar SG, Krishnan KM, Deshmukh SC. Hook plate fixation for type II fractures of the lateral end of the clavicle. Journal of shoulder and elbow surgery. 2006 Jul 1;15(4):419-23. 
19. Shin SJ, Roh KJ, Kim JO, Sohn HS. Treatment of unstable distal clavicle fractures using two suture anchors and suture tension bands. Injury. 2009 Dec 1;40(12):1308-12.

20. Kalamaras M, Cutbush K, Robinson M. A method for internal fixation of unstable distal clavicle fractures: early observations using a new technique. Journal of shoulder and elbow surgery. 2008 Jan 1;17(1):60-2.

21. Chen CH, Chen WJ, Shih CH. Surgical treatment for distal clavicle fracture with coracoclavicular ligament disruption. Journal of Trauma and Acute Care Surgery. 2002 Jan 1;52(1):72-8.

22. Bezer M, Aydin N, Guven O. The treatment of distal clavicle fractures with coracoclavicular ligament disruption: a report of 10 cases. Journal of orthopaedic trauma. 2005 Sep 1;19(8):5248.

23. Ballmer FT, Gerber C. Coracoclavicular screw fixation for unstable fractures of the distal clavicle. A report of five cases. The Journal of bone and joint surgery. British volume. 1991 Mar;73(2):291-4.
24. Macheras G, Kateros KT, Savvidou OD, Sofianos J, Papagelopoulos PJ, Fawzy EA. Coracoclavicular screw fixation for unstable distal clavicle fractures. Orthopedics. 2005 Jul 1;28(7):6936.

25. Rieser GR, Edwards K, Gould GC, Markert RJ, Goswami T, Rubino LJ. Distal-third clavicle fracture fixation: a biomechanical evaluation of fixation. Journal of shoulder and elbow surgery. 2013 Jun 1;22(6):848-55.

26. Anderson K. Evaluation and treatment of distal clavicle fractures. Clinics in sports medicine. 2003 Apr;22(2):319-26.

27. Canadian OT. Nonoperative treatment compared with plate fixation of displaced midshaft clavicular fractures: A multicenter, randomized clinical trial. The Journal of bone and joint surgery. American volume. 2007 Jan;89(1):1.

28. Kapil-Mani KC, Acharya P, Arun S. Precontoured Clavicular Locking Plate with Broad Lateral End: A Newly Designed Plate for Lateral Third Clavicle Fractures. Malaysian orthopaedic journal. 2018 Mar;12(1):15. 